\title{
Finite Element Analysis of Mechanical Characteristics of Dropped Eggs Based on Fluid-Solid Coupling Theory
}

\author{
Song Haiyan, ${ }^{1,2}$ Wang Fang, ${ }^{3}$ Zhang Jianguo, ${ }^{3}$ Zhang Yinong, ${ }^{3}$ and Yang Shugang ${ }^{3}$ \\ ${ }^{1}$ College of Packaging and Printing Engineering, Tianjin University of Science \& Technology, Tianjin 300222, China \\ ${ }^{2}$ China Key Laboratory of Food Packaging Materials and Technology in Light Industry, Tianjin 300222, China \\ ${ }^{3}$ College of Mechanical Engineering, Tianjin University of Science \& Technology, Key Laboratory of Integrated Design and \\ Online Monitoring of Light Industry and Food Machinery and Equipment in Tianjin, Tianjin 300222, China
}

Correspondence should be addressed to Song Haiyan; songhaiyan00@126.com

Received 23 December 2016; Accepted 1 June 2017; Published 12 July 2017

Academic Editor: Ivo Caliò

Copyright (C) 2017 Song Haiyan et al. This is an open access article distributed under the Creative Commons Attribution License, which permits unrestricted use, distribution, and reproduction in any medium, provided the original work is properly cited.

It is important to study the properties and mechanics of egg drop impacts in order to reduce egg loss during processing and logistics and to provide a basis for the protective packaging of egg products. In this paper, we present the results of our study of the effects of the structural parameters on the mechanical properties of an egg using a finite element model of the egg. Based on Fluid-Solid coupling theory, a finite element model of an egg was constructed using ADINA, a finite element calculation and analysis software package. To simplify the model, the internal fluid of the egg was considered to be a homogeneous substance. The egg drop impact was simulated by the coupling solution, and the feasibility of the model was verified by comparison with the experimental results of a drop test. In summary, the modeling scheme was shown to be feasible and the simulation results provide a theoretical basis for the optimum design of egg packaging and egg processing equipment.

\section{Introduction}

An egg has the shape of an approximate ellipse whose curvature radius is larger at one side than at the other. Consequently, they are liable to roll around and are extremely fragile. In order to avoid the loss of eggs due to collisions or large vibrations, it is necessary to place the eggs in cushioning materials while they are collected, graded, packaged, processed, stored, transported, and traded. Egg damage is primarily caused by dynamic loading, such as drops, collisions, and vibrations. Statistics show that the damage rate of eggs during processing is $3.7 \%$, and the loss rate caused by eggshell cracks is $6-8 \%$, although some microcracks remain invisible. When the losses from other causes are also taken into account, such as deterioration due to improper storage, the economic loss to China amounts to RMB 500 million yuan every year $[1,2]$. Therefore, research into the mechanical properties of eggs when they are subjected to drop impacts is important in order to reduce egg loss and provide a basis for the protective packaging of egg products.
Several studies have been conducted at home and abroad on the static characteristics of eggs. For example, as early as 1986, Upadhyaya et al. [3] measured the basic physical parameters of eggshells with the following results: the egg size and egg-shape index (the ratio of the major axis to the minor axis of an egg) had an impact on the static compressive strength of an egg; the smaller end of the egg, which served as the compression end, was able to bear a larger load under static compression [4]; the thickness of the eggshell greatly affected the maximum loading capacity; the curvature radius at the vertex of each end of the egg correlated significantly with the maximum loading capacity, which increased as the curvature radius increased [5].

In terms of the dynamics, Liu and $\mathrm{Wu}[6]$ analyzed the dynamic characteristics of the egg, including the physical quantities, the stress and deformation under static pressure, and the maximum height from which the egg can be dropped without damage onto various materials. They also proposed a means to describe the damage to the egg based on the dynamic load with energy. In 2004, Kemps et al. [7] experimentally measured the resonant frequency of an 
eggshell based on a theoretical formula for the effect of the dimensions of the eggshell and the modulus of elasticity on the resonant frequency. Wang [8] utilized a bounce table and a data acquisition unit in order to analyze the impact characteristics associated with dropping eggs and to identify the law of variation between the various factors, such as different drop heights, impact areas, cushioning materials, thickness of the cushioning materials, and peak values of the impact force and impact time. In 2011, Chen [9] conducted an inclined tumbling impact experiment with eggs and analyzed the relationship between the egg-shape index, the curvature radius at the midpoint, and the symmetry of the damage area in the single-factor and orthogonal experiments by changing the length, height, and materials of the inclined plane. To analyze the dynamic mechanical properties of the egg, Teixeira and Awruch [10] used a numerical simulation of the fluid-solid coupling system by means of the finite element method, conducted a numerical analysis of that system in Arbitrary Lagrangian-Eulerian (ALE) equations using the Taylor-Galerkin method, and verified their correctness with two numerical examples, that is, a compressible fluid and a slightly compressible fluid. With the model analysis based on the experiments, $\mathrm{Wu}$ [11] calculated the resonant frequency and the corresponding damping ratio of the egg and described the vibrational response of the egg caused by a slight mechanical impact in the direction of its equator. In 2010, Perianu et al. [12] simulated a numerical model of the eggshell and the liquid load within the egg using the finite element method. He concluded that the geometrical parameters of the egg, such as the eggshell thickness and egg size, had a large impact on the natural frequency of the fluidsolid coupling of the egg.

In order to analyze the characteristics of the natural frequency of a watermelon, Nourain et al. [13] created a finite element model. Dintwa et al. [14] studied the possibility of modeling errors when simulating postharvest packaging in bulk using a discrete element method and constructed a finite element model to analyze the dynamic process of collision between individual apples and that between the apples and the wall. Zhang et al. [15] conducted research into the design and mechanical properties of a PVC elastic thinwalled packing box for eggs.

The majority of the existing theoretical models or numerical simulations established for the dynamic characteristics of eggs failed to take the fluid within the egg into consideration. Instead, they have paid an excessive amount of attention to the eggshell and static compression and dropping force analyses. In this paper, we describe the results of an indepth finite element analysis into the mechanical properties of the egg and its associated damage mechanisms in order to provide more comprehensive theoretical guidance on solving egg damage problems in practice.

\section{Establishment and Verification of a Finite Element Model of the Fluid-Solid Coupling System in an Egg}

2.1. Establishment of the Geometric Model of an Egg. An egg consists of an eggshell, eggshell membrane, egg white,

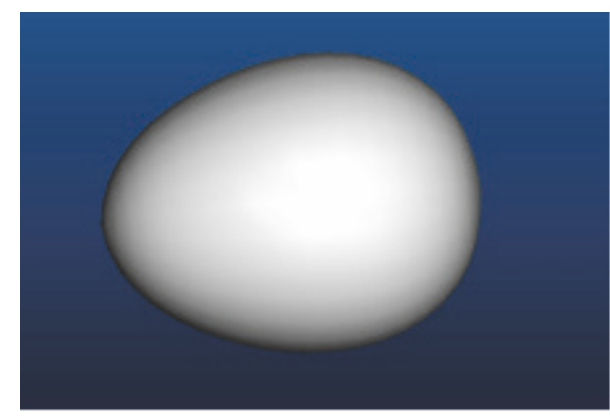

Figure 1: The shape of egg amending in Pro/E.

and egg yolk, of which the eggshell and membrane together represent $10-13 \%$, the egg white represents $55-60 \%$, and the yolk represents $32-35 \%$ of the total weight of the egg.

The typical parameters used for modeling an egg are the weight: $50 \mathrm{~g}$, eggshell thickness: $0.35 \mathrm{~mm}$, diameter of the major axis: $58.5 \mathrm{~mm}$, diameter of minor axis: $45 \mathrm{~mm}$, and eggshape index $R$ (the ratio of the major axis to minor axis of the egg): 1.3. Due to the fact that an egg is an irregular ellipsoid, as indicated in Figure 1, a 3D CaMega five-axis automatic optical scanning system was used during the modeling process to acquire the actual contour data, automatically generate a correct external geometric model of the egg, and establish a 3D model of the fluid inside the egg in the Pro/Engineer software tool in order to create a realistic geometric model of the egg. To simplify the model, the fluid within the eggshell was defined as a homogeneous fluid.

\subsection{Mesh Generation and Boundary Conditions of the Egg} Model. The eggshell and cushioning material models were established in the ADINA Structure module using the shell element. The eggshell and cushioning material were divided into 3,575 and 1,600 units, respectively. The internal fluid model of the egg was built using the ADINA-CFD 3D-fluid element, and the internal fluid was divided into 53,760 units. In order to simplify the model, internal fluid was assumed to be a homogeneous substance. The finite element model is shown in Figure 2.

\subsection{Establishment of the Material Properties and Boundary} Conditions. Parameters have been defined for the cushioning material and eggshell. A universal biomechanical test machine (INSTRON 3369) was used to test the mechanical properties with an elastic modulus of $0.578 \mathrm{MPa}$. According to the calculation standards for a curved surface published by the American Society of Agricultural Engineers [16] and other relevant literature, the elastic modulus of an eggshell is $E=3.0 \times 10^{4} \mathrm{MPa}$, Poisson's ratio $\mu=0.25$, the eggshell density $\rho=2.532 \mathrm{~g} / \mathrm{cm}^{3}[17]$, and the entire egg was measured to weigh $50 \mathrm{~g}$. See Table 1 for a list of the other materials in the egg $[18,19]$.

The contact between the eggshell and the plane of the cushioning material was defined, the internal curve of the eggshell was defined as a fluid-solid coupling boundary, the four edges of the cushioning material were fully constrained, 
TABLE 1: Data regarding the eggshell, egg yolks, and protein.

\begin{tabular}{lccc}
\hline & $\begin{array}{c}\text { Specific heat } \\
(\mathrm{J} / \mathrm{kg} \cdot \mathrm{K})\end{array}$ & $\begin{array}{c}\text { Density } \\
\left(\mathrm{kg} / \mathrm{m}^{3}\right)\end{array}$ & $\begin{array}{c}\text { Viscosity } \\
(\mathrm{kg} / \mathrm{m} \cdot \mathrm{s})\end{array}$ \\
\hline Egg shell & 888 & 2300 & - \\
Egg yolks & 3560 & 1035 & $1.6-4.8 \times 10^{-3} \mathrm{~T}$ \\
Egg protein & 3560 & $-0.0074 T^{2}-0.0039 T+1038.9$ & $3.12-8.9 \times 10^{-3} \mathrm{~T}$ \\
\hline
\end{tabular}
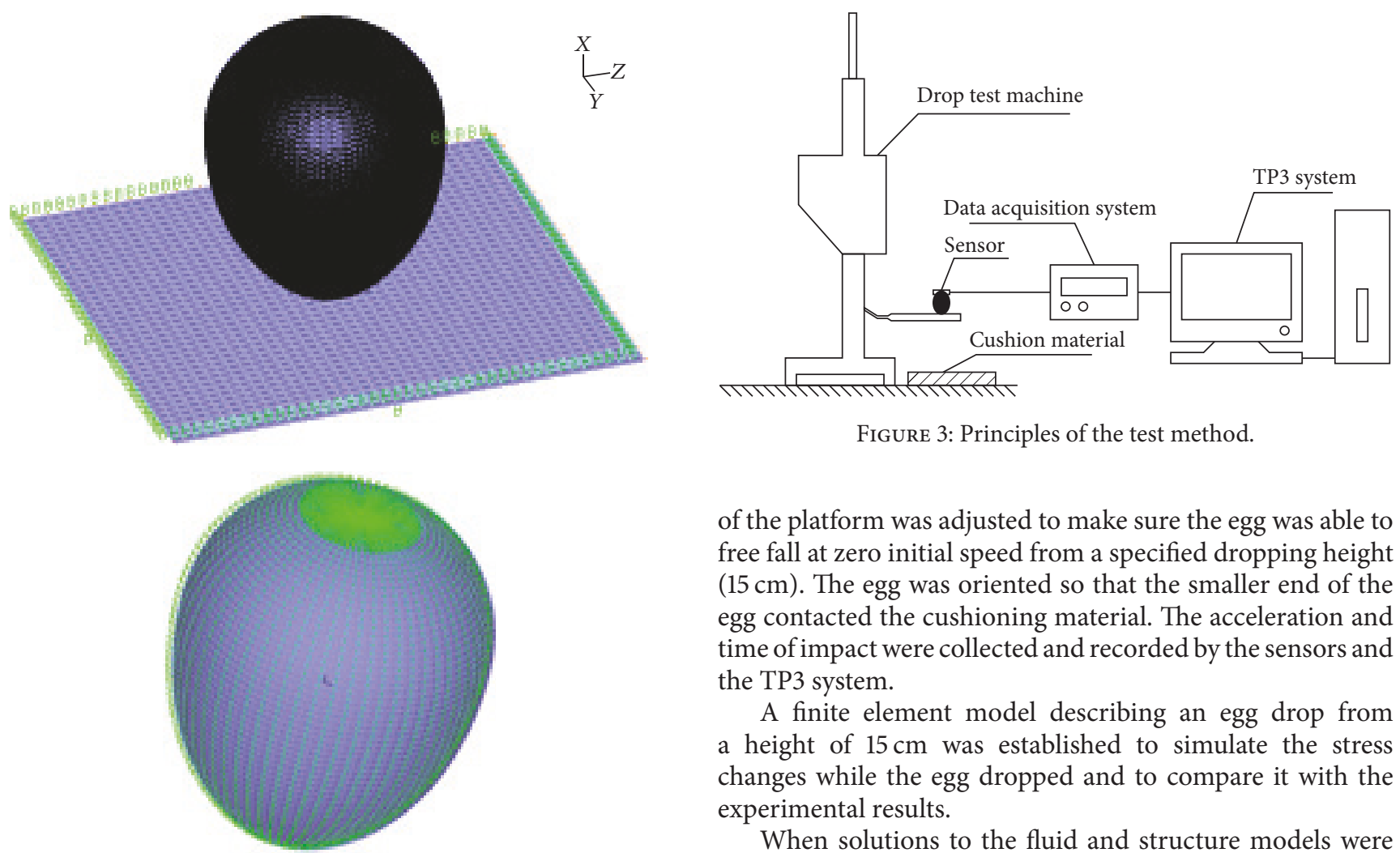

Figure 3: Principles of the test method.

of the platform was adjusted to make sure the egg was able to free fall at zero initial speed from a specified dropping height $(15 \mathrm{~cm})$. The egg was oriented so that the smaller end of the egg contacted the cushioning material. The acceleration and time of impact were collected and recorded by the sensors and the TP3 system.

A finite element model describing an egg drop from a height of $15 \mathrm{~cm}$ was established to simulate the stress changes while the egg dropped and to compare it with the experimental results.

When solutions to the fluid and structure models were

FIGURE 2: The mapped meshing of the structure and fluid models.

the internal fluid was simplified by assuming it was homogeneous, and the fluid-structure interaction (FSI) fluid-solid coupling boundary and free surface were taken as boundary conditions.

2.4. Model Verification. Fresh eggs with sizes and shape values similar to the model characteristics were selected for the experiment. After measuring the numerical values of major and minor axes of those eggs, there were five eggs whose egg-shape indices $(R)$ were close to 1.3 and weights that were approximately $50 \mathrm{~g}$. These were used as the experimental subjects. EPE foam with a thickness of $48 \mathrm{~mm}$ and an elastic modulus of $0.578 \mathrm{MPa}$ was used as the cushioning material.

The equipment used for the experiment included a drop test machine, PCB tri-direction transducer, and TP3 data acquisition system (LANSMONT Corporation).

As shown in Figure 3, the PCB tri-direction transducer was fixed to the larger end of the egg while ensuring that the surface where the transducer contacted the egg was perpendicular to the direction of the drop. The egg was placed on the test platform of the drop test machine, and the height found, the fluid-solid coupling boundary conditions in both models were recovered. In terms of the boundary conditions of the structure, the internal surface of the eggshell was assumed to be a fluid-solid coupling interface, the surface that contacted the eggshell was selected as a fluid-solid variable section, and the free surface was selected as the boundary condition for the liquid level at which the fluid model contacted the air chamber. Those two models were coupled into the ADINA fluid-solid coupling solver (ADINA-FSI) in order to find solutions and to determine the nephogram of the stress on the eggshell, as shown in Figure 4. As shown in the figure, when the egg was dropped onto the EPE foam from a height of $15 \mathrm{~cm}$, the stress at the contact point increased proportionally to the contact surface between the egg and cushioning material. The maximum stress of the impact on the smaller end of the egg spread in the direction of the larger end. Because it was based on an actual object, the geometric model of the eggshell had a certain asymmetry, which is why the stress distribution on the eggshell was uneven when the stress was applied.

As shown in Figure 5, the circumferential displacement of the eggshell was calculated by means of a simulation. The range of the circumferential displacement of the eggshell was $-0.136 \mathrm{~mm}$ to $0.18 \mathrm{~mm}$. 


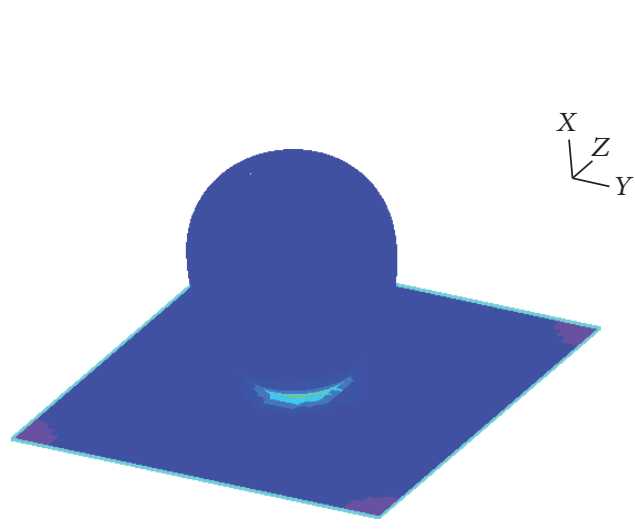

Maximum

$\triangle 5.471 E+09$

EG 1. EL 2018.JPT $222(4.634 E+09)$

Minimum

* 227.9

EG 2. EL 1600.JPT 112 (258.2)

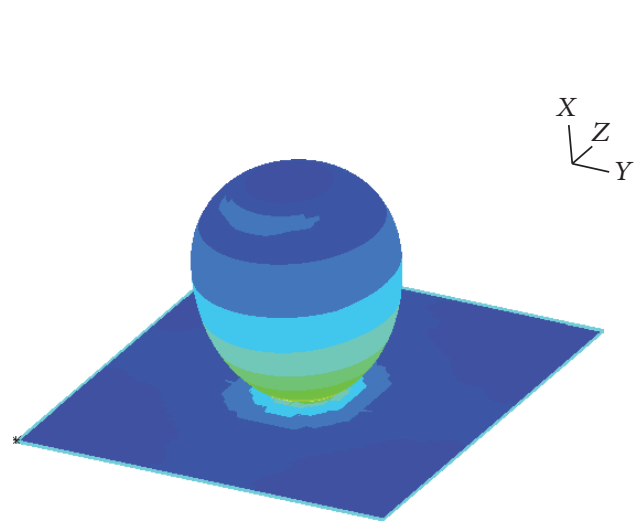

Effective stress R5T CALC

Shell $T=1.00$

Time 0.06750

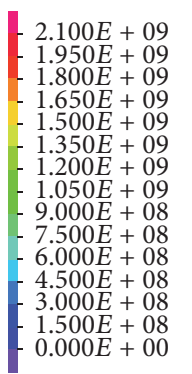

Maximum

$\triangle 5.467 E+09$

EG 1. EL 3383.JPT $222(4.824 E+09)$

Minimum

* 91050 .

EG 2. EL 40.JPT 122 (5532198.)

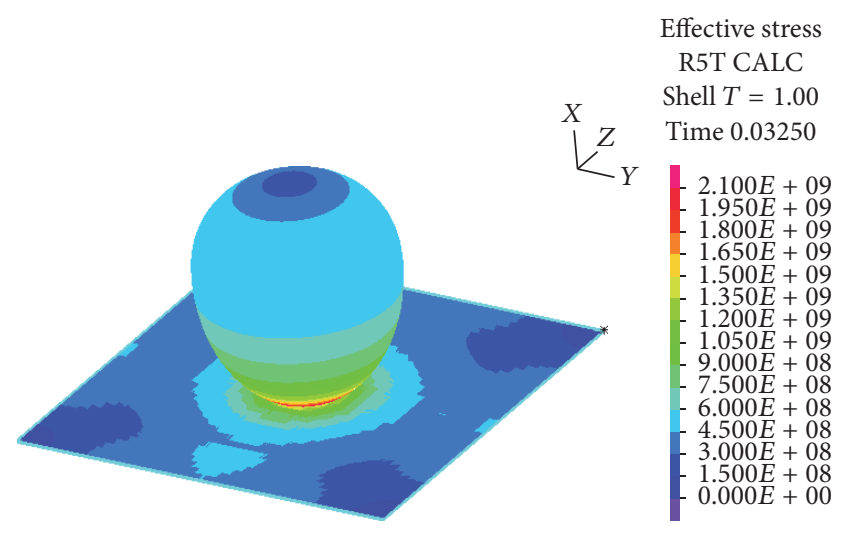

Maximum

$\triangle 7.568 E+09$

EG 1. EL 914.JPT $222(6.727 E+09)$

Minimum

* 147448 .

EG 2. EL 1561.JPT $212(1.122 E+07)$

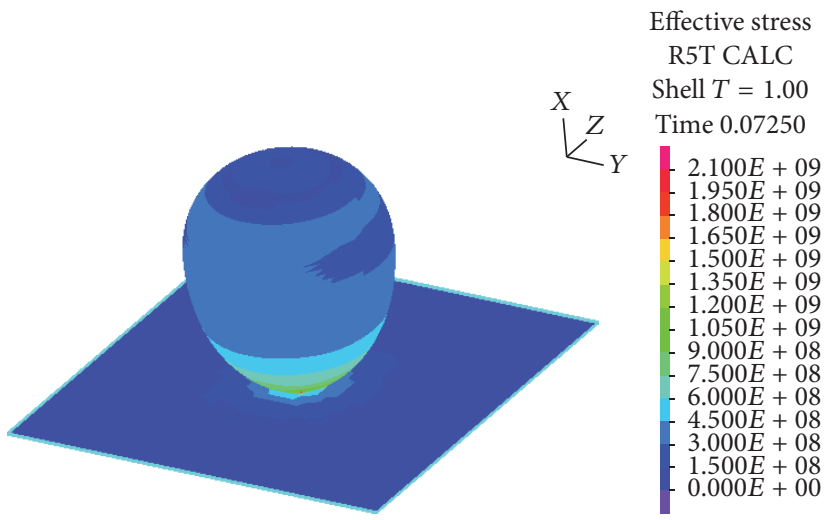

Maximum

$\triangle 4.544 E+09$

EG 1. EL 3383.JPT $222(4.073 E+09)$

Minimum

* 234219 .

EG 2. EL 1600.JPT 112 (4293388.)

Figure 4: The nephogram of the effective stress of the egg on the EPE from a height of $15 \mathrm{~cm}$.

Figure 6 shows a comparison between the simulation results and the experimental data. In the figure, the ordinate represents the acceleration $\left(\mathrm{m} / \mathrm{s}^{2}\right)$ and the abscissa represents the time step. As is indicated by the simulation curve, the maximum acceleration was $373.6 \mathrm{~m} / \mathrm{s}^{2}$. In comparison, the experimental data showed that the maximum acceleration of the egg was $353.9 \mathrm{~m} / \mathrm{s}^{2}$ when it was dropped onto the EPE cushioning material from a height of $15 \mathrm{~cm}$. These results show that the error between the simulation results and the experimental data was less than $6 \%$.

\section{Drop Height Limit Analysis Based on the Finite Element Model of the Egg}

The value of the initial drop speed was adjusted by changing the boundary conditions in the structure and fluid models.
The simulation results of the eggshell when the egg was dropped and the speed value when the eggshell failed were calculated by the FSI solver when the drop height limit for the egg and the EPE cushioning material could be obtained.

When a drop test was conducted at a height of 40 and $45 \mathrm{~cm}$, the corresponding initial impact speeds in the finite element model were $2.8 \mathrm{~m} / \mathrm{s}$ and $2.97 \mathrm{~m} / \mathrm{s}$, respectively. The simulation result indicated that the egg did not crack when it was dropped at an impact speed of $2.8 \mathrm{~m} / \mathrm{s}$, whereas the egg cracked when the speed reached $2.97 \mathrm{~m} / \mathrm{s}$. When the initial impact speed was lowered to $2.89 \mathrm{~m} / \mathrm{s}$, which was the initial speed of the model, there was nonconvergence after the 15th iteration during the solution procedure, which indicated that the egg was subject to a maximum impact when it contacted the EPE cushioning material from a corresponding height of $42.6 \mathrm{~cm}$. It was then observed that the egg cracked when it 


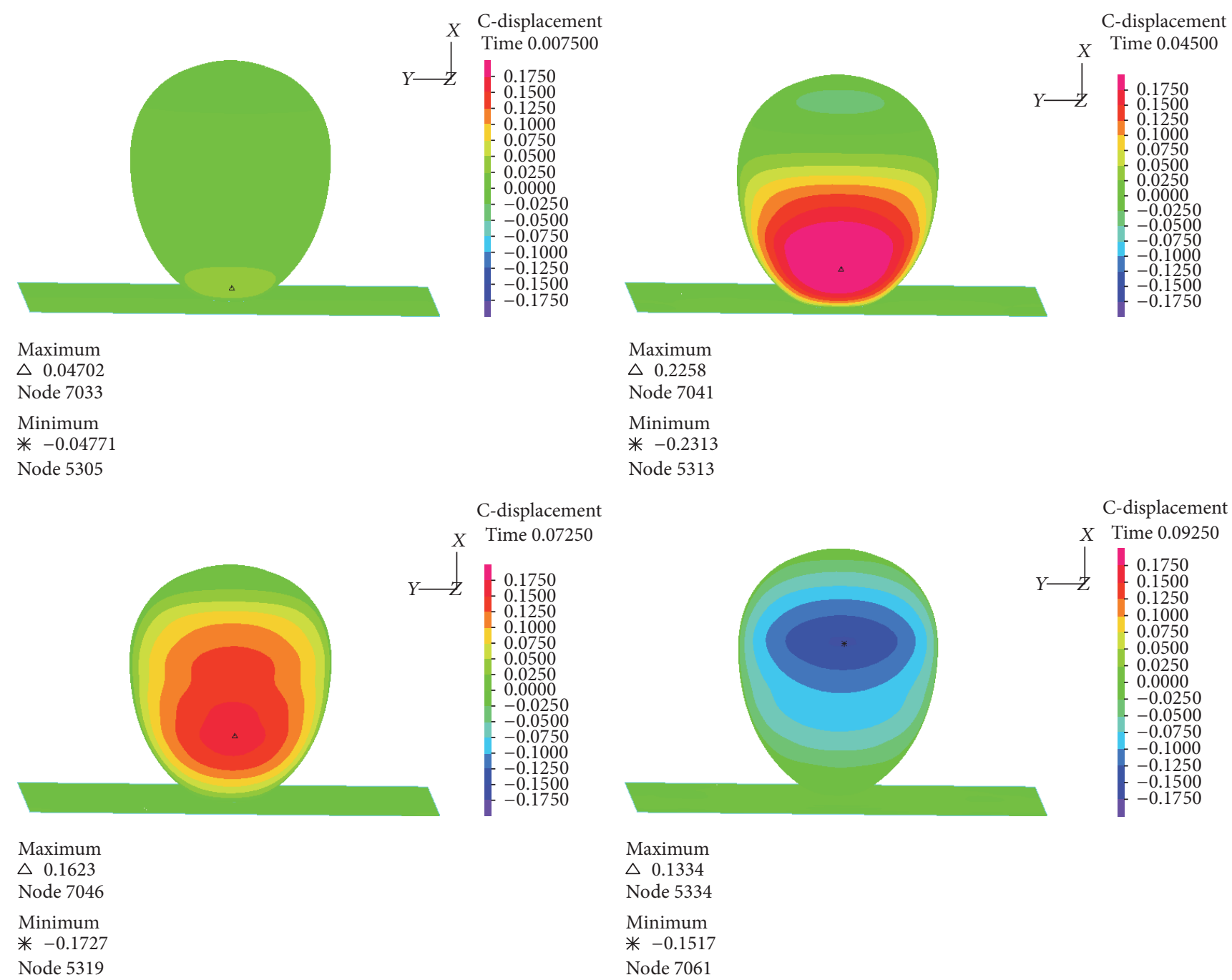

Figure 5: The meridional displacement nephogram of the eggshell.

was dropped onto the EPE cushioning material from a height of $42.6 \mathrm{~cm}$. As shown in Figure 7, there was damage to the smaller end of the egg because of the excessive stress.

\section{Conclusions}

(1) The egg was assumed to be a linearly rotating thin-walled structure with isotropic properties and a uniform thickness based on an analysis of previous analytical and research work locally and abroad that focused on a numerical model of the egg. A 3DCaMega five-axis automatic optical scanning system was used to scan the contour of the egg. The complete contoured surface of the egg was generated by means of reverse engineering, which simplified the modeling process.

(2) ADINA, a finite element analysis software package, was used to build a finite element model of the egg based on the principles of fluid-solid coupling. With a coupled solution, the software was used to simulate a drop impact of the egg. The feasibility of this model for use in a mechanical property simulation of drop impact was verified by the drop experiment. A comparison between the simulation and experimental results showed that the error in the simulation was less than $6 \%$, which means that the model can be used in a realistic simulation.

(3) Based on the simulation, the height limit that an egg could survive without cracking when it was dropped onto EPE cushioning material was $42.6 \mathrm{~cm}$, which was determined by modifying the initial conditions of the model based on a fluid-solid coupling model. The simulation results of this model will serve as a theoretical foundation and provide guidance for studies on egg protective packaging and the optimization of the design of egg processing equipment.

\section{Disclosure}

Wang Fang is the coauthor. Song Haiyan and Wang Fang are both the first authors of this manuscript.

\section{Conflicts of Interest}

The authors declare that there are no conflicts of interest regarding the publication of this paper. 


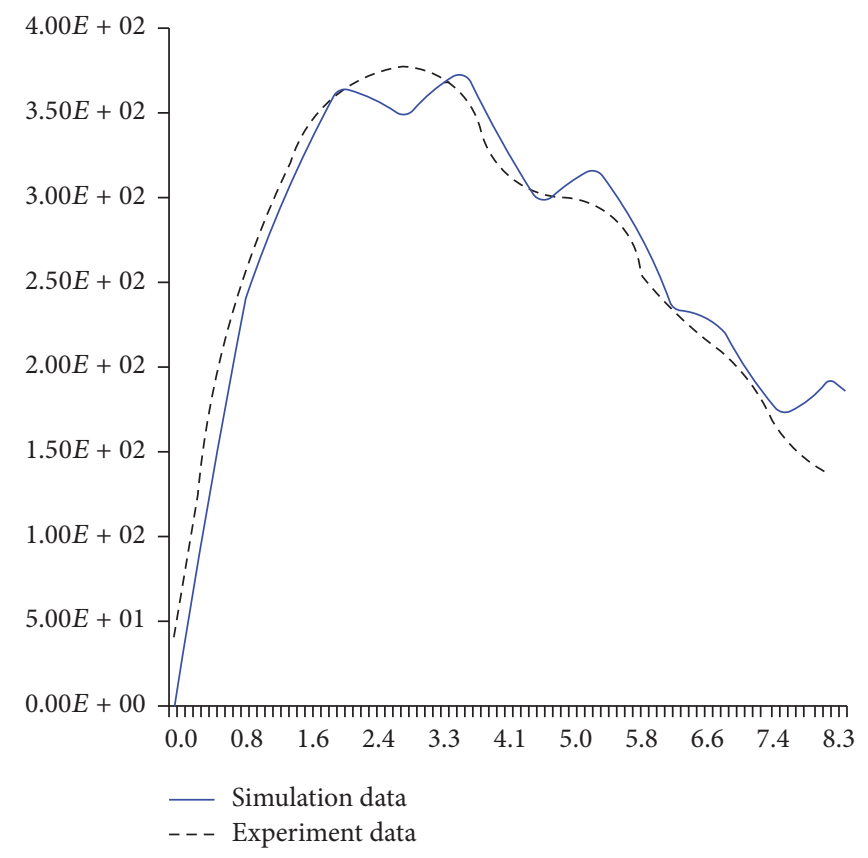

FIGURE 6: Contrast of the simulation and test results.

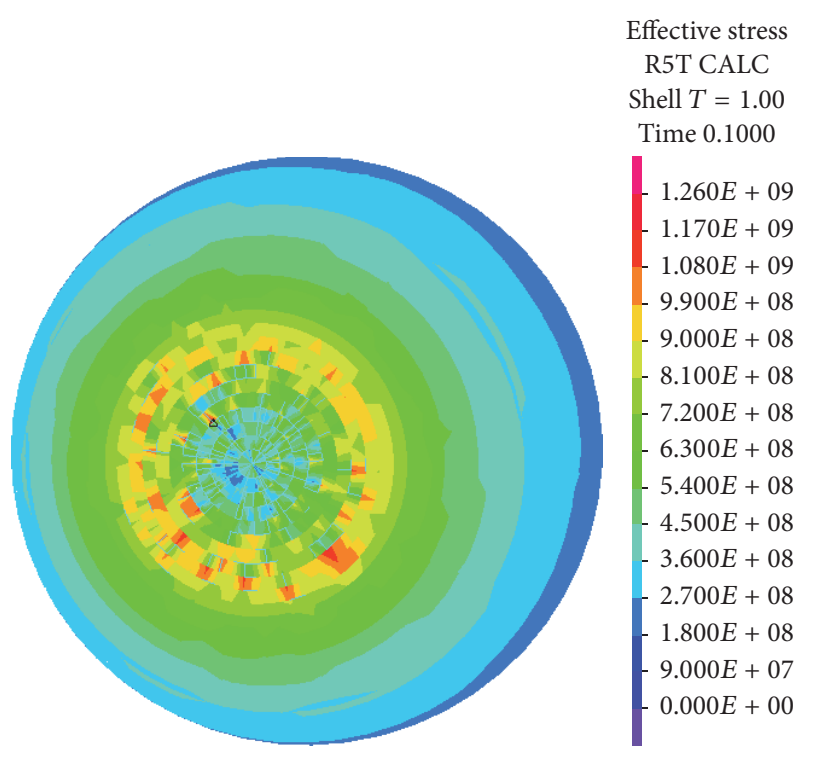

Maximum

$\triangle 1.294 E+09$

EG 1. EL 1825.JPT $212(1.133 E+09)$

Minimum

* $5.666 E+07$

EG 1. EL 2535.JPT $32(5.688 E+07)$

FIgURE 7: The failure of the eggshell when dropped onto the EPE cushioning material from a height of $42.6 \mathrm{~cm}$.

\section{Acknowledgments}

The authors acknowledge National Sci-Tech Support Plan Program of the "12th Five-year Plan" (2015BAD16B05); Tianjin Application Foundation and Cutting-Edge Technology Research Program (13JCZDJC30900); Tianjin Fundamental
Research Funds for the Comprehensive Investment in "13th Five-Year"; Tianjin Food Safety and Low-Carbon Manufacture Collaborative Innovation Center; China Key Laboratory of Food Packaging Materials and Technology in Light Industry.

\section{References}

[1] H.-Z. Song, J. Wang, and J.-A. Ye, "Analysis of the loading properties of fowl eggshell with finite element method," Journal of Zhejiang University, vol. 32, no. 3, pp. 350-354, 2006.

[2] Y. Ren, Research on Biomechanics of Eggs Based on Shape Characteristics, Huazhong Agriculture University, Wuhan, China, 2007.

[3] S. K. Upadhyaya, J. R. Cooke, R. S. Gates, and R. H. Rand, "A finite element analysis of the mechanical and thermal strength of avian eggs," Journal of Agricultural Engineering Research, vol. 33, no. 1, pp. 57-78, 1986.

[4] X. Hu, H. Chen, and Y. Ren, "Static mechanical characteristic of chicken egg," China Poultry, vol. 29, no. 10, pp. 19-25, 2007.

[5] Z. Cui, Egg Static Load Characteristics Analysis and Study on Finite Elemen, Jiangsu University, Zhenjiang, China, 2009.

[6] X. Liu and S. Wu, "Experimental analysis on mechanical properties of eggs," Journal of Jiangsu Institute of Technology, vol. 13, no. 1, pp. 7-13, 1992.

[7] B. Kemps, B. De Ketelaere, F. Bamelis et al., "Development of a methodology for the calculation of young's modulus of eggshell using vibration measurements," Biosystems Engineering, vol. 89, no. 2, pp. 215-221, 2004.

[8] Y. Wang, Study on Shock Characteristic of Chicken Egg, Huazhong Agriculture University, Wuhan, China, 2007.

[9] J. Chen, Research on the Relationship between Eggshell Morphology and Impact Mechanical Charaeteristies, Huazhong Agriculture University, Wuhan, China, 2011.

[10] P. R. F. Teixeira and A. M. Awruch, "Numerical simulation of fluid-structure interaction using the finite element method," Computers and Fluids, vol. 34, no. 2, pp. 249-273, 2005.

[11] B. Wu, "CFD simulation of mixing in egg-shaped anaerobic digesters," Water Research, vol. 44, no. 5, pp. 1507-1519, 2010.

[12] C. Perianu, B. De Ketelaere, B. Pluymers, W. Desmet, J. DeBaerdemaeker, and E. Decuypere, "Finite element approach for simulating the dynamic mechanical behaviour of a chicken egg," Biosystems Engineering, vol. 106, no. 1, pp. 79-85, 2010.

[13] J. Nourain, Y. Ying, J. Wang et al., "Finite element models of watermelon and their applications," Transactions of the Chinese Society of Agricultural Engineering, vol. 21, no. 1, pp. 17-22, 2005.

[14] E. Dintwa, M. Van Zeebroeck, H. Ramon, and E. Tijskens, "Finite element analysis of the dynamic collision of apple fruit," Postharvest Biology and Technology, vol. 49, no. 2, pp. 260-276, 2008.

[15] R. Zhang, S. Wang, and Z. Mei, "Design of PVC elastic thin wall packing box for eggs and experiment of its mechanical property," Transactions of the Chinese Society of Agricultural Engineering, vol. 32, no. 7, pp. 252-257, 2016 (Chinese).

[16] America Society of Agricultural Engineer. Compression Test of Food Materials of Convex Shape. ASAE Standarde, 2003: 596603.

[17] W. T. Tsai, J. M. Yang, C. W. Lai, Y. H. Cheng, C. C. Lin, and C. W. Yeh, "Characterization and adsorption properties of eggshells and eggshell membrane," Bioresource Technology, vol. 97, no. 3, pp. 488-493, 2006. 
[18] C. M. Sabliov, B. E. Farkas, K. M. Keener, and P. A. Curtis, "Cooling of shell eggs with cryogenic carbon dioxide: A finite element analysis of heat transfer," LWT - Food Science and Technology, vol. 35, no. 7, pp. 568-574, 2002.

[19] S. Denys, J. G. Pieters, and K. Dewettinck, "Computational fluid dynamics analysis of combined conductive and convective heat transfer in model eggs," Journal of Food Engineering, vol. 63, no. 3, pp. 281-290, 2004. 


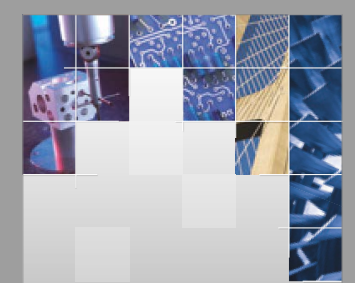

\section{Enfincering}
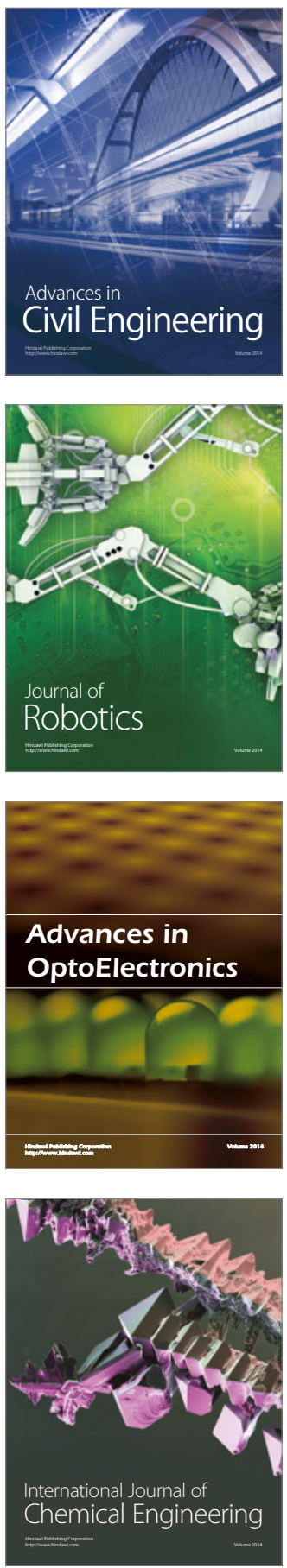

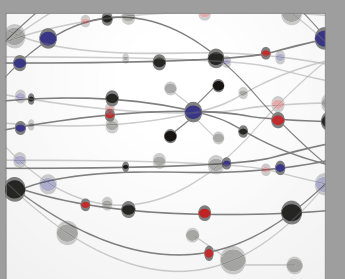

The Scientific World Journal

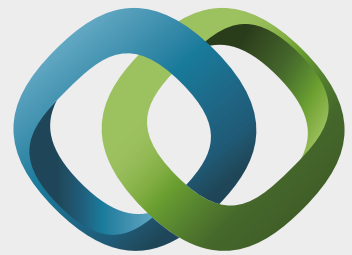

\section{Hindawi}

Submit your manuscripts at

https://www.hindawi.com
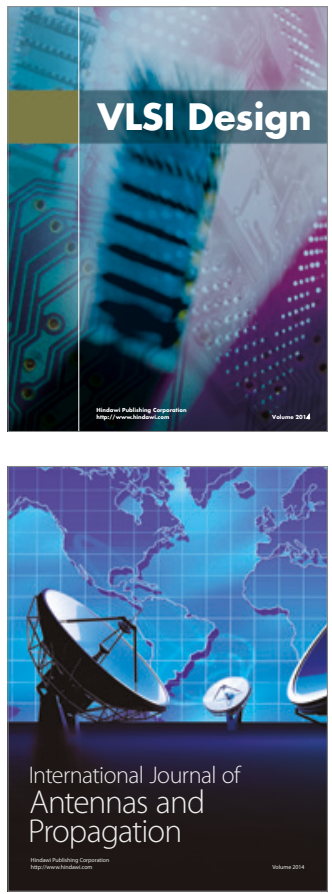

\section{Rotating}

Machinery
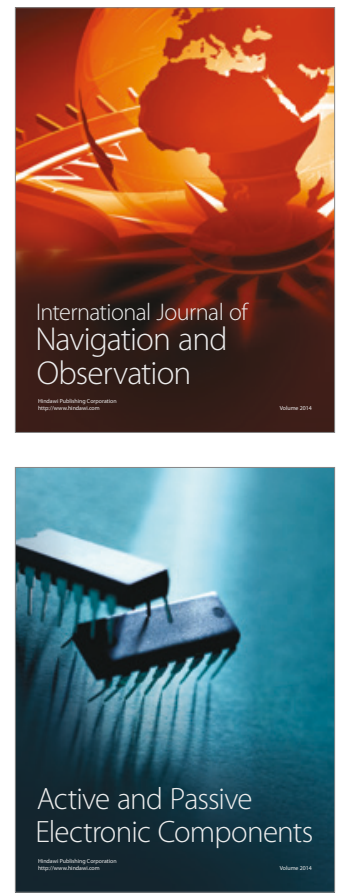
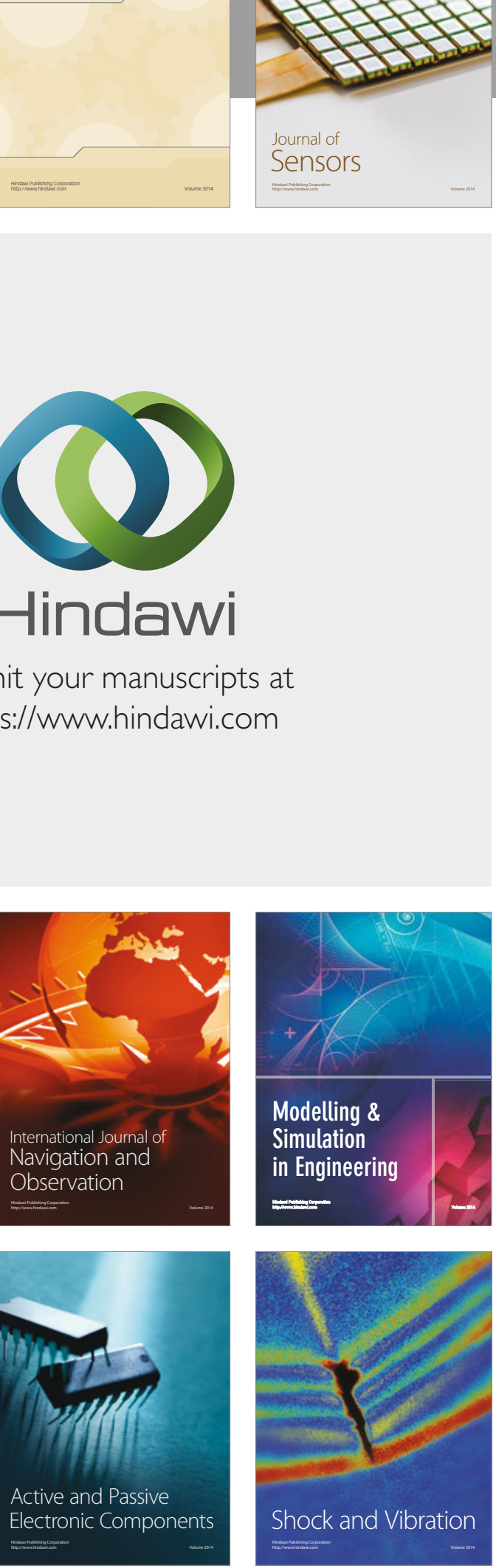
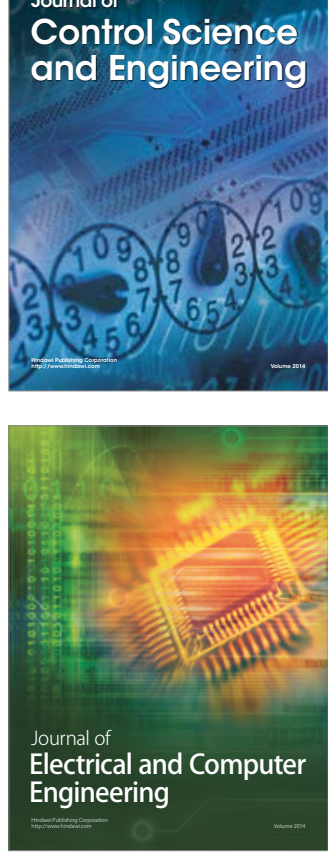

Distributed

Journal of

Control Science

and Engineering
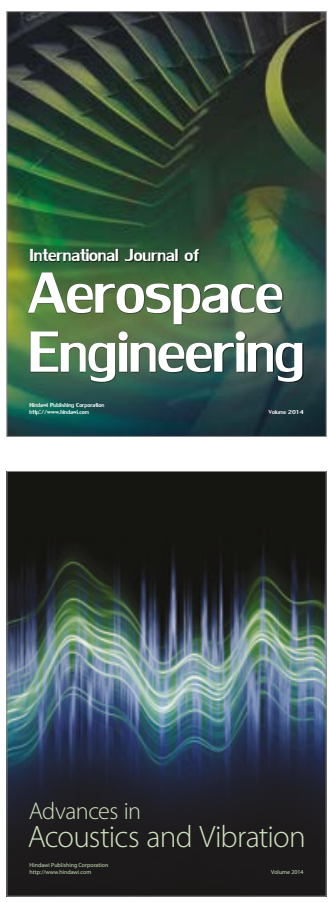

Sensor Networks 